\title{
RECONCILING WORK AND FAMILY IN THE CONTEXT OF BOUNDARYLESS CAREERS: ACADEMIC CAREERS IN SOCIAL SCIENCES AND HUMANITIES
}

\section{Abstract}

This paper considers the extent to which men and women with PhDs reconcile work and family life in boundaryless careers in academia. The paper is based on a study of European PhD graduates in social sciences and humanities. The paper identifies three features of boundaryless careers in academia (1) inter-organizational mobility (2) international mobility and (3) boundaryless working hours. The results showed that, whilst many people appreciated the autonomy in academic careers, the insecurity, long hours and need for mobility caused conflicts between work and family life. This affected both men and women, but, due to traditional gender roles, difficulties combining academic careers with families affected women disproportionately.

Key words: boundaryless careers, academic careers, women.

\section{Resumo}

Conciliação trabalho/família no contexto de carreiras sem fronteiras: carreiras académicas nas ciências sociais e humanas

Este artigo analisa a medida em que homens e mulheres com doutoramento conciliam trabalho e vida familiar em carreiras sem fronteiras na academia. $\mathrm{O}$ artigo é baseado num estudo com titulares de um doutoramento em ciências sociais e humanas na Europa. São identificadas três características das carreiras sem fronteiras na academia: (1) mobilidade interorganizacional; (2) mobilidade internacional e (3) horas de trabalho sem fronteiras. Os resultados mostraram que, enquanto muitas pessoas apreciaram a autonomia em carreiras académicas, a insegurança, as longas horas de trabalho e a necessidade de mobilidade estavam na origem de conflitos entre trabalho e vida familiar. Isto afetava tanto homens como mulheres, mas, devido a papéis de género tradicionais, as dificuldades de combinar carreiras académicas com as famílias afetava desproporcionadamente as mulheres.

Palavras-chave: carreiras sem fronteiras, carreiras académicas, mulheres.

\section{Résumé}

La conciliation travail-famille dans le contexte des carrières sans frontière: des carrières universitaire dans les sciences humaines et sociales

Cet article considère dans quelle mesure les hommes et les femmes avec un doctorat arrivent à concilier le travail et la famille dans les carrières sans frontières. Basé sur une étude de docteurs en sciences sociales et humaines, l'article identifie trois aspects de car-

Knowledge and Place Research Group, University of Salford, Salford M6 6PU, UK.

E-mail: d.m.millard@me.com

Postal address: University of Salford, Mary Seacole Building, Frederick Road Campus, Salford M6 6PU, UK. 
rières académiques sans frontières (1) la mobilité inter-organisationnelle (2) la mobilité internationale (3) les heures de travail sans frontières. Les résultats montrent que certains chercheurs apprécient l'autonomie associée avec les carrières académiques, mais, en même temps, les chercheurs ont du mal à concilier le travail et la famille à cause de l'insécurité, les heures longues de travail et le besoin d'être mobile. Ceci affecte les hommes ainsi que les femmes, mais, donnant les rôles traditionnels, les difficultés à combiner les carrières académiques avec la famille ont un effet plus important sur les femmes.

Mots-clés: carriers sans frontières; carriers académiques; femmes.

\section{Introduction}

The concept of boundaryless careers gained currency in the 1990s, following Michael Arthur's (1994) article describing changing employment patterns that go beyond the boundaries of single employment settings. Arthur's definition of boundaryless careers included inter-organizational mobility, inter-organizational networking, validation from outside the organization, break-down of hierarchies and rejection of traditional boundaries for personal reasons. Boundaryless careers put the onus on individuals rather than organizations to manage their career. According to Phillip Brown et al. (2003), there are two conflicting views of this perspective. Whilst consensus theory supports the idea of employability in a knowledge economy, conflict theory emphasizes the insecurity faced by people who have few job guarantees.

Yahuda Baruch and Douglas Hall (2004) argue that academic careers capture many aspects of boundaryless careers that have become prevalent in business, since they have long been based outside the scope of careers built in organizations. Validation comes from publications and reputation (Rodrigues and Guest 2010), inter-organizational mobility is common, and inter-organizational networking is central to careers. Careers are associated with autonomy and creativity and there are opportunities to travel and network internationally. However, it can take many years to develop careers, causing insecurity, and long working hours and pressures for international mobility can cause conflicts in the reconciliation of work and family life.

There is much data showing that women are in the minority in academic careers, particularly at senior levels, even in areas such as life sciences and social sciences and humanities where they are well represented at $\mathrm{PhD}$ level. This supports the view that academic careers are unattractive to women. The dropout of women from academic careers is often attributed to difficulties reconciling work and family life (Mason and Goulden 2004; Hewlett et al., 2008; Fox et al., 2011).

This paper is based on a study of careers, mobilities and impacts of PhD graduates in social sciences and humanities (SSH) in Europe. It seeks to contribute by (1) Improving understanding of the boundaries of careers, moving beyond discussion of inter-organizational mobility and identifying three aspects 
of boundaryless careers, inter-organizational mobility, geographical mobility and boundaryless working hours; (2) Presenting empirical evidence on how people view career boundaries. The paper is based on a large European study of 13 countries, and therefore takes a European perspective not restricted to only one or two countries; (3) Improving understanding of the conflicts faced by women leading to them rejecting academic careers.

Based on interviews with PhD graduates in SSH in 9 countries (Germany, Hungary, Latvia, Norway, Poland, Portugal, Slovakia, Switzerland and UK) of the 13 included in the study, the aim in this paper is to understand features of boundaryless careers and to what extent they are compatible with family life in academic careers of PhD graduates. The first two sections will present literature on boundaryless careers, focusing on academic careers. They are followed by a section that will review literature on women in academic and scientific careers. The Methodology will then be presented, followed by the Results, based on interviews with $\mathrm{SSH} \mathrm{PhD}$ graduates.

\section{Boundaryless careers}

Brown et al. (2003) term work reorganization in the past 20 years as the democratisation of insecurity', whereby professionals, as well as semi-skilled and unskilled workers, have found that lifelong careers no longer exist. Arthur (1994) described six aspects of boundaryless careers: (1) Inter-organizational job mobility; (2) Validation coming from outside the employer (3) Careers sustained by inter-organizational networks (4) Breaking down of traditional hierarchical career boundaries (5) Rejection of existing opportunities for personal reasons; (6) Perceiving a boundaryless career future regardless of structural constraints. However, it is argued that boundaryless careers have often been understood mainly as physical mobility, in particular between organizations (Rodrigues and Guest 2010; Gubler et al. 2014).

As a result of these new employment structures, it is suggested that people develop skills that are relevant to a range of organizations rather than one. Robert DeFillippi and Michael Arthur (1994) argue that the three core competencies of know why, know how and know who are valuable in this context. Know why relates to beliefs, values and identities. Know how is related to skills and jobrelated knowledge. Know who relates to networking. For careers built in one organization, all of these may have developed to suit specific organizational cultures, skills requirements and hierarchies. In the context of 'boundaryless careers', these competences would be employed in a range of settings.

However, it has been questioned whether careers have really become boundaryless. If interpreted as only increased inter-organizational mobility, Rodrigues and Guest (2010) find little evidence of change. In reality, there is likely to be considerable variation between countries, sectors and individual 
career paths. It is argued by some that boundarylessness has long since characterised work in some sectors, including film-making, construction, semi-conductors, software writing and academia (DeFillippi and Arthur 1998; Baruch and Hall 2004). Career structures also vary considerably across countries, with different levels of social protection and different approaches to hire and fire for example, not least within the EU, where the extent of inter-organizational mobility varies. Yahuda Baruch and Christina Reis (2015) identify the two trends of «new careers» and the globalization of careers, arguing that both exist alongside traditional careers.

There are also opposing views on the extent to which boundaryless careers are beneficial. The concept of boundaryless careers highlights the role of individual agency in managing careers (Brown et al. 2003; Sommerlund and Boutaiba 2007; Rodrigues and Guest 2010). According to Brown et al. (2003), this can be viewed in two contrasting ways. Based on consensus theory, technology is seen as the driving force of social change. In the new knowledge economy, knowledge is viewed as the key source of competitive advantage. The emphasis on employability reflects the demand for technical, scientific and professional workers who require lifelong learning. Therefore, there is a growing number of managerial, professional and research careers and a greater emphasis on recruiting talent, regardless of class, gender, race or ethnicity. Based on conflict theory, on the other hand, employability is an attempt to legitimate unequal opportunities in education and work. The responsibility for employment, training and careers is placed on the individual, with organizations no longer taking responsibility for the welfare of workers. This causes insecurity and, according to Brown et al. (2003), restricts, rather than enhances, freedom of individuals, since, whilst they may be free to change employers, they are not free from the need to earn a living.

\section{Boundaryless careers and academia}

Academic careers display many aspects of 'boundarylessness' based on Arthur's definition, notably: inter-organizational mobility, validation from outside the employer and sustained by inter-organizational networks. Other features have some aspects of commonality with academic careers. Academic hierarchies are relatively flat (Baruch and Hall 2004; Sommerlund and Boutaiba 2007). Regarding the fifth aspect, that people reject existing career opportunities for personal reasons, this could apply to academia, since people working in academia may prefer the autonomy and flexible working hours common in academia. According to Baruch and Hall (2004), the academic career model can serve as a role model to the concept of boundaryless careers. They argue that the 'intelligent' career - knowing why, knowing how and knowing who - has always been part of the intrinsic nature of academic work. They particularly highlight the importance of inter-organizational networking, with professional 
reference, rather than hierarchical position defining roles in teams, and selfguided career transitions unbounded by one organization. They highlight other features of academic careers, including flat structure, empowerment and autonomy, multi-directional career paths, the use of the sabbatical, multiple career paths, knowledge management, career practices (e.g. mentoring), use of alternative work arrangements (e.g. telecommuting and flexitime), and labour markets (based on globally agreed standards).

Some authors find evidence of boundaried and boundaryless careers in academia (Dowd and Kaplan 2005; Sommerlund and Boutaiba 2007; Baruch and Reis 2015). People follow different career paths even within academia. In this paper, the focus is on boundaryless careers and knowledge creation. If people focus on creating new knowledge, organizational and international boundaries, and working hours are not relevant. It is argued by Jean-Baptiste Meyer et al. (2001) that international science mobility is based on the principle that access to the latest knowledge worldwide necessitates international networking and travel. It is also necessary to work according to the needs of the research, irrespective of any fixed working hours. Success is measured by productivity, factors such as publications and citations being the international benchmark. However, this does not necessarily apply to so-called 'locals' (Dowd and Kaplan 2005). Teaching only faculty in less-research focused universities may have boundaried careers. There are again likely to be variations between different countries, related to factors such as the research environment and labour market characteristics.

Whilst the consensus view of boundaryless careers supports equal opportunities, arguing that there is a search for talent regardless of class, gender, race and ethnicity (Brown et al. 2003), the conflict view highlights the insecurity of boundaryless careers. Baruch and Hall's (2004) analysis suggests that many aspects of academic careers have the potential to make them more equal to different groups, including relatively flat structures and early adoption of alternative work arrangements, such as home and flexible working. However, they point out that it is unclear how progressive the academic model has been in allowing women and other under-represented groups to break the glass ceiling, the evidence suggesting that it has not been as progressive as one might hope, as will now be discussed.

\section{Women and academic careers}

Data on women in academic careers show that 47 percent of PhDs were awarded to women in the EU in 2012. There is some variation by country with higher representation of women in many Southern and Eastern European countries. Of the countries discussed in this paper, Latvia (59.9\%) had the highest share of women, followed by Portugal (56.3\%). Other countries above 47 percent of women PhD graduates were Poland (53\%) Slovakia (49\%), and Norway (48\%). 
The other countries were below 47 percent: Hungary and the UK (46\%), Germany $(45 \%)$ and Switzerland (43\%). Women are under-represented in most fields of science and engineering, with the exception of life sciences. There are also fewer women in academic posts, and particularly at senior level. In 2011, women in the EU accounted for only $33 \%$ of researchers and only $21 \%$ at the most senior research grade (grade A), again with some variation by country (European Commission 2016).

In social sciences and humanities there is a more even gender balance in the early career stages with women making up 51 percent of $\mathrm{PhD}$ graduates in the EU in social sciences, business and law, and 55 percent in the arts and humanities. However, this puts into focus the dropout of women at higher levels, since they made up only 30 percent of the most senior research grade (grade A) in humanities and 23.5 percent in social sciences. Whereas, in many fields of science and technology, the problem relates to encouraging girls and women to take up the subject, in social science and humanities, the dropout occurs after the PhD, implying that some features of academic careers discourage women.

A large literature seeks to explain the dropout of women from science and academic careers. Surveys have often found that women in academic careers are less satisfied than men with their work (e.g. Hewlett et al. 2008; Hill et al. 2010; Perista and Perista 2014). It is argued here that this can be explained by features of 'boundaryless careers' related to inter-organizational mobility, geographical mobility and boundaryless working hours.

Firstly, inter-organizational mobility is common prior to obtaining tenure (e.g. Ackers and Oliver 2007). The PhD can be followed by several years of temporary postdocs and lengthy processes to obtain tenure, which results in insecurity, but also lack of financial compensation more common in corporate careers. This insecure period without a permanent contract can often be at the age when people are having children, so women face the decision of having children whilst in insecure positions, finding a more secure position outside academia first or postponing having children. This can be exacerbated by the need for mobility to secure a position. Pressures for inter-organizational mobility can continue postPhD and postdoc, with variations between countries. In some countries, in particular Germany and Austria, a 'Habilitation' is often a requirement for an academic post and there is a need to move to a different institution at this point. In the UK, inter-organizational mobility is common in order to obtain promotion.

Secondly, the demands for geographical mobility, in particular international mobility and sometimes encompassing inter-organizational mobility, present a barrier for people with caring responsibilities (Ackers 2010). In academia, this includes mobility to move to postdoctoral positions prior to securing tender, but continues later into the career. It includes short-term mobility, for example to attend conferences and collaboration meetings, medium-term fellowships and research visits, and more permanent moves aimed at career advancement. According to the She Figures 2015 (European Commission 2016), women 
researchers in the EU are less mobile from the postdoc period, although their mobility levels are similar to men prior to this. During their PhD, 17.6 percent of women and 18.9 percent of men had moved abroad for at least 3 months, whereas at the post-PhD phase, 34.2 percent of men had experienced mobility of at least 3 months compared to 25.1 percent of women. Mobility is a particular issue when women have partners and families. It has been shown that women scientists frequently marry other scientists (Mason and Goulden 2004; Ceci et al. 2014), more so than men. This presents issues of dual careers. If one of the couple moves for a postdoc or other position, it may be difficult for the partner to find a suitable position. Therefore, they have to make choices between foregoing the opportunity, one of the two sacrificing or postponing the career, down-skilling or living apart. Whilst it is an issue for men and women, it affects women more, since they are more likely to be married to a scientist and are more likely to be the main carers of small children. Living with children away from extended family also means they may have less family support and childcare options. Shortterm mobility may be difficult for women with children because they need to arrange childcare. However, it is also suggested that academic careers afford a certain amount of autonomy to make these mobility decisions (Ackers 2008; Cañibano et. al. 2013).

The third issue is the long working hours associated with academic careers. Whilst working hours are flexible, it is a normative expectation that work is a high priority (Fox et al. 2011). This presents conflicts for women who have been shown to devote more time to domestic and caring duties (e.g. Mason and Goulden 2004; Perista and Perista 2014). Hours worked in science are not only long, but also unpredictable (Buchinger et al. 2002; Ackers 2007), although home working is more of an option in SSH than in science and technology, where there may be a greater need for presence in the laboratory. The need to achieve in terms of careers can place demands on people at the age where scientists and academics are starting families, particularly between the ages of 30 and 40. According to Mason and Goulden (2004), «It is the long hours and required travel, precisely at the time when women with advanced degrees have children and begin families, that force women to leave the fast track professions» $(2004,88)$.

According to the She Figures 2012 (European Commission 2013), part-time working could be a factor slowing the progression of women. Failure to work long hours may reduce research productivity. According to Ceci et al. (2014), research has shown that men generally publish more than women and this gap has only narrowed slightly over time. Some evidence has also shown that research funding awarded to women is less. As well as possibly less hours worked, this could also be due to having less time to network. This may include socializing after work or at weekends (Ackers 2007), when people, especially women with small children, may not be available (Ceci et al. 2014). Women might suffer lack of progression because they take time out for maternity or reduce their hours to care for children even temporarily. According to David Lubinski 
and Camilla Benbow (2007), in fast-paced science and technology careers with high knowledge decay, it is hard to take time out. Being out of science careers temporarily can reduce overall productivity. Further, taking time out could exclude women from networks besides being absent when decisions are made.

The discussion has highlighted some of the main features of boundaryless careers identified in academic research careers: notably inter-organizational mobility and networking, evaluation based on productivity, boundarylessness in terms of geography (international networking and travel), and boundarylessness in terms of hours worked. There is a high degree of autonomy, but also high demands in terms of productivity and flexibility, with associated pressures to be mobile, to work long hours and generally to organize life around work. This will be discussed based on empirical work with people who have completed PhDs in social sciences and humanities in the Results Section. Before this, the Methodology and sample will be described.

\section{Methodology}

The paper is based on a European (FP7) funded project entitled, 'Mapping the Population, Careers, Mobilities and Impacts of Advanced Research Degree Graduates in the Social Sciences and Humanities' (POCARIM), which included 13 countries; France, Germany, Hungary, Italy, Latvia, Norway, Poland, Portugal, Slovakia, Spain, Switzerland, Turkey and the UK. The project involved (1) a literature review, (2) a policy review, (3) a data review, (4) a survey of around $2700 \mathrm{PhD}$ graduates in social sciences and humanities, and (5) a total of 325 follow-up interviews. The survey was carried out in July-August 2012 and interviews in late 2012 to early 2013.

The survey was based on sampling for diversity, since it was not considered feasible to survey a representative sample. A sample was selected according to the following criteria: (1) from each broadly defined discipline; (2) balance of males and females; (3) people employed in academia, the private sector, government and the third sector; (4) people from different higher education institutions based on rankings; (5) varied geographical locations within countries. Respondents to the survey were 47 percent male and 52 percent female. Most of them (57\%) had obtained their PhD in 2008-12, and successively less going back each year. The majority $(70 \%)$ obtained their $\mathrm{PhD}$ in social sciences, worked in the public sector $(76 \%)$ and in a higher education or research institution (78\%). Just 7.4 percent worked in business and 6.8 percent in government. The survey included questions about career history, current role, international mobility, inter-sectoral mobility and combining work with family. Qualitative follow-up interviews were completed with a selection (at least 25) from each country, in order to explore attitudes in greater depth. Interviews were selected purposefully from the survey respondents, to include slightly higher proportions with experi- 
ence of the main topics of the research, including international and inter-sectoral mobility, research impact and combining work with family. Of people interviewed, 60 percent were in higher education, 12 percent in the private sector, 9.4 percent in government and 5 percent in NGOs.

This paper reports on the interviews. The data was analysed with a qualitative software package (NVivo). Interviews were coded into themes, which included reconciling work with family. This revealed that the main issues related to (1) the need for inter-organizational mobility, in particular in the early career stage; (2) the need for geographical mobility, and (3) long and unboundaried working hours. Interviews were therefore coded further into these categories. It was decided to restrict the countries to the following: Germany, Hungary, Latvia, Norway, Poland, Portugal, Slovakia, Switzerland and the UK, accounting for 225 interviews (the country is indicated in brackets after the quotations). This was because the qualitative data was quite rich from these countries and also allowed quite a broad coverage of Europe, including of female representation in PhD graduates. They included some of the countries with the highest (Latvia and Portugal) and lowest proportions of women (Germany and Switzerland). Of these interviews, 52 percent of the respondents were female and 48 percent male.

\section{Results}

\section{Inter-organizational mobility}

Inter-organizational mobility is a particular feature of academic careers in the early years but can continue throughout the career. The interviews revealed that many people faced obstacles in developing an academic career due to long career paths; several years in higher education followed by at least three years working towards a $\mathrm{PhD}$, and frequently one or more fixed term research posts. Therefore, it is not just a concern for young people, but can continue into midcareer. This was mentioned by researchers from several countries, but was a particular concern for respondents from Germany due to the length of time needed to complete a PhD and the need to obtain a Habilitation. Difficulties in obtaining a permanent contract in academia or in science may push people to seek work in other sectors, as expressed by the following two people:

The problem is that when you work for 6 or 7 years for your $\mathrm{PhD}$ and an additional 10 years for your Habilitation, then you are around 42 or something. And you have nothing, you only saw academia your whole life [male DE16].

If it turns out there are no possibilities of obtaining a permanent position at a university, I'd say that in future I'm not a complete stranger to thinking of leaving academia in order to get a more secure work position [male NO06]. 
In Germany this is also associated with geographical mobility as explained for example by the following:

After the PhD you need to, I would say in the Germany university, you need to move around and go to a different place and have a place as an assistant professor somewhere else and then you might be able to come back [female DE12].

They highlight the insecurity that comes from several years in temporary research posts. Some point out that this can result in lack of social benefits, such as the following woman: «I'm 39, going to be 40 next year .... I have no pension and this is ... where the temptation to move away from academia to try and find something ... that's permanent» [female UK29].

Social benefits are often not as attractive in academic as corporate careers as expressed by the following:

If I stayed at [multinational firm], I could work part-time during my maternity leave. If I come back after a year and a half, I would get two months' salary in advance. They have great benefits. In that sense it would be good to stay there. I would like to try as many departments as I can so I can get a chance of a career growth. Everything works there and the benefits are really good [female SK12]

\section{Geographical mobility}

In highly skilled and highly specialized labour markets, such as academia, inter-organizational mobility is often associated with geographical mobility both within country and internationally. This can apply not only to academic careers, but also to other highly skilled careers. Whilst there may be more autonomy to make decisions in academic careers, career paths can be long, and pay and conditions are often not as lucrative as in the private sector.

A variety of types of mobility exist, including fellowships, sabbaticals, conference travel and travel to collaboration meetings. The main concern expressed in the interviews related to moving for short-term contracts. In many cases, both partners are professionals and there is a need to accommodate two careers. The need to move for short-term contracts can be detrimental for their partners' career and as a result for the financial security of the family. This is a major concern for people with small children as commented by many people, for example the following three:

I had two children. So to go abroad with the Swiss National Science Foundation postdocs is not an option because my husband couldn't follow ... if you are a postdoc you get paid very little by the Swiss National Science Foundation [female CH01].

In our field it's difficult to relocate ... We would need a really good grant to enable us to support our family and set up our life in another country [male HU04]. 
Definitely while the children are small and my husband has a job [moving abroad] is ruled out [female PL09].

The pressure to be mobile can lead to the attrition of women, as explained by the following:

Q: Can you tell me more about why you decided against the academic route at that point?

A: I think it was mainly the obligations this kind of career would have implied. On the one hand, there's the need for mobility, both short-term mobility in terms of going to conferences, but also probably for a longer research stay abroad. I think if you really would have followed this academic career and by then I was already in touch with some American universities, I probably would have to go also over to an American university and take my family or go on my own. So it was just not family compatible [female DE11].

A few people commented that short-term travel, for example to conferences was a possibility, but could be difficult to organize with small children, for example the following: «I love these mobility experiences but they are, of course, difficult to manage and I have had to refuse several things» [female PT10].

\section{Boundaryless working hours}

Autonomy and academic freedom is one of the factors that make academic careers attractive, and can be an advantage in terms of organizing family life. This was seen as an advantage by a number of people, for example the following:

Being an academic allows me to be flexible with respect to family life. It doesn't mean that I work less but my work hours are more flexible. So if my child is ill and I have to stay home for a couple of days then I just do that and I don't even have to inform anybody [female DE13].

I partly work at home and partly in the university, this is actually ideal for a family with small children [male DE25].

However, as discussed in the literature review, there is a normative expectation that the career is a high priority. This often causes conflict for women in particular, who are more likely to want to work part-time when they have small children, such as the following:

It plays an important role because actually I am not, I don't want to work more than $70 \%$ and I think because I consider it important for me that I have at least one day a week with my children [female $\mathrm{CH} 02$ ]. 
A number of people argued that having children reduces time for work and can impact on overall productivity, for example the following two people:

Twice that I had to publish, I had twice a baby. And then I thought that I could maybe publish later or while I had the maternity leave, and that was just not possible [female CH01].

If I do something with my children the whole weekend and I don't do any work that has a deadline, it can respectively affect in some way my income ... I really am not happy that I am in a way forced to do that [male LV09].

The boundarylessness of working hours can result in the expectation that people are always available, including evenings, weekends and during holidays. Some women did not have time for after-work socialising, where work contacts may arise. This can affect men and women, but gendered roles and cultural expectations mean they are felt to a lesser degree by men, as explained by the following woman: «One of the problems for women who had children was that the department meeting started at $5 \mathrm{pm}$ and went on until $9 \mathrm{pm}$. This is the worst time for people with children. So why not move meetings like that?» [female DE12].

The discussion of working hours reveals that working hours are flexible, with the potential to organize working hours around family, which was seen as an advantage by some. However, for others this was a disincentive to an academic career due to the need to always be available. Further, the expectation that work is a high priority is reflected in the demands for academic productivity. This affects men and women, but women face additional barriers due to time taken for maternity leave and having greater caring responsibilities than men.

\section{Discussion}

In academia, the aim is to develop new knowledge, validated by the international scientific community. In this paper, three main features of boundaryless careers in academia were highlighted: inter-organizational mobility, geographical mobility, and boundaryless working hours. Whilst inter-organizational mobility and, to a lesser extent, geographical mobility are discussed in literature on boundaryless careers, boundaryless working hours has not been a focus.

The main motivation for inter-organizational mobility in academic careers is to develop skills, knowledge and networks. In early career stages this often involves a number of fixed-term research contracts following a PhD. However, the period of fixed-term contracts can often extend into mid-career. This varies between countries, but in some countries there can be pressures to make longerterm moves into mid-career. Many research-active academics also continue to 
experience short, medium and long-term mobility. This often also involves international mobility. In order to access the latest knowledge, academics travel to conferences, workshops and meetings, and in some cases may wish to undertake fellowships, particularly in early career, but also in mid-career. Working hours are flexible, and can be described as boundaryless. This has the potential to afford flexibility in organizing family life, however also involves working round the needs of research in terms of meeting deadlines, travel (which may take in evenings and weekends) and other research constraints; thus they do not necessarily allow greater flexibility. Success is measured by productivity, in particular publications, citations and research funding, which is also, to a large extent, a function of hours worked.

This presents problems when academics have families, in particular young children. Whereas some people interviewed in this research speak of the autonomy and flexibility, there is more emphasis on the problems that this brings in terms of (1) insecurity associated with fixed term contracts, (2) the need to be mobile and travel internationally, and (3) the long working hours involved. These affect men and women, but appear to affect women more because of cultural norms that women are the primary carers. Insecurity and difficulties securing tender are a disincentive to men and women to pursue academic careers. Many researchers spoke of the need for stability when they had small children, which meant they could not continue to undertake a succession of short-term fellowships. The need for travel and long hours appear to affect women more, in particular when they have young children. They are then generally less available to undertake international mobility, in particular for longer periods. They speak of difficulties reconciling long working hours with family life. This is not only about long working weeks, but also about working hours that are not compatible with family. This is an issue for women in particular, because they may be temporarily less present or unavailable for maternity leave or when children are small. Even if this is only for a temporary period, this tends to reduce their overall productivity, and they may fail to progress during critical periods of their career. It appears from this research, that the need for mobility for fixed-term fellowships offers the greatest challenge. Short-term travel appears to be a concern, but more easily manageable. The impact of boundaryless working hours is mixed; it can be an advantage in terms of flexibility but a disadvantage in terms of long working hours cultures.

There is some variation between disciplines and between countries. In social sciences and humanities (also some areas of science and technology), there is the possibility to work from home and to work flexible hours. In some disciplines there is less of a need for multiple postdocs than in others. The academic labour market varies between countries, with differences between the US and Europe and within Europe. Working hours culture and mobility pressures also vary between countries. 


\section{Conclusion}

In conclusion, highly skilled knowledge intensive academic research careers tend to not be bounded by organization, place or time. Academic careers illustrate well the debate between the consensus and conflict views of employability and boundaryless careers in the knowledge economy. Whilst they involve autonomy and creativity, they are also associated with insecurity. There are features than can make them open to women; evaluation is based on productivity, they are relatively flat hierarchically, and working hours and patterns are flexible. Flexible hours can be an advantage if the academic has some control over them, but this is not always the case. The dropout of women at successive career stages, in particular in SSH where they make up around half of $\mathrm{PhD}$ graduates, supports the idea that boundaryless academic careers are not attractive to them. This 'boundarylessness' causes conflicts in work-life balance and can lead to the attrition of women. These findings could be tested with further research that might involve both large quantitative studies and more detailed qualitative comparative studies to further explore how men and women see the boundaries of highly skilled and academic careers in different countries and different disciplines.

\section{Bibliographical References}

Ackers, Louise. 2007. «Legislating for equality: Working hours and progression in science careers». European Law Journal 13(2): 169-185. DOI: https:/ / doi.org/10.1111/j.14680386.2007.00362.x

Ackers, Louise. 2008. «Internationalisation, Mobility and Metrics: A new form of indirect discrimination». Minerva 46(4): 411-435. DOI: https: / / doi.org/10.1007/s11024-008-9110-2

Ackers, Louise. 2010. «Internationalisation and Equality: The contribution of short stay mobility to progression in science careers». Recherches Sociologiques et Anthropologiques 41(1): 83-103. DOI: https: / / doi.org/10.4000/rsa.189

Ackers, Louise, and Liz Oliver. 2007. «From flexicurity to flexsecquality? The impact of fixed-term contract provisions on employment in science». International Studies of Management $\mathcal{E}$ Organization 37(1): 53-79. DOI: https:/ / doi.org/10.2753/IMO00208825370103

Arthur, Michael B. 1994. «The boundaryless career: A new perspective for organizational inquiry». Journal of Organizational Behavior 15(4): 295-306. DOI: https:/ / doi.org/ 10.1002 / job.4030150402

Baruch, Yehuda, and Douglas T. Hall. 2004. «The academic career: A model for future careers in other sectors». Journal of Vocational Behaviour 64(2): 241-262. DOI: https: / / doi.org/10.1016/j.jvb.2002.11.002

Baruch, Yehuda, and Christina Reis. 2015. «How global are boundaryless careers and how boundaryless are global careers? Challenges and a theoretical perspective». Thunderbird International Business Review 58(1): 13-27. DOI: https:/ / doi.org/10.1002/ tie.21712

Brown, Phillip, Anthony Hesketh, and Sara Williams. 2003. «Employability in a knowledge-driven economy». Journal of Education and Work 16(2), 107-126. DOI: https: / / doi.org / 10.1080/1363908032000070648 
Buchinger, Birgit, Doris Gödl, and Ulrike Gschwandtner. 2002. Berufskarrieren von Frauen und Männern an österreichs, Universitäten. Eine sozialwissenschaftliche Studie über die Verienbarkeit von Beruf und Privatem. Wien: Bundesministerium für Bildung, Wissenschaft und Kultur.

Cañibano, Carolina, Mary. F. Fox, and Javier Otamendi. 2013. "Gender aspects of researchers' international mobility». Paper presented at the EU-SPRI Forum Conference on Management of Innovation Policies, Madrid, April 12-13.

Ceci, Stephen J., Donna K. Ginther, Shulamit Kahn, and Wendy M. Williams. 2014. «Women in academic science: A changing landscape». Psychological Science in the Public Interest 15(3): 75-141. DOI: https: / / doi.org/10.1177/1529100614541236

DeFillippi, Robert J., and Michael B. Arthur. 1994. «The boundaryless career: A competency-based perspective». Journal of Organizational Behaviour 15(4): 307-324. DOI: https:/ / doi.org/10.1002/job.4030150403

DeFillippi, Robert J., and Michael B. Arthur. 1998. «Paradox in project-based enterprise: The case of filmmaking». California Management Review 40(2): 125-139. DOI: https: / / doi.org/10.2307/41165936

Dowd, Karen O., and David M. Kaplan. 2005. «The career life of academics: Boundaried or boundaryless?» Human Relations 58(6): 699-721. DOI: https: / / doi.org/10.1177/ 0018726705057156

European Commission. 2013. She Figures 2012: Gender in research and innovation, statistics and indicators. Luxembourg: Publications Office of the European Union. Available at https: / / ec.europa.eu / research/science-society / document_library / pdf_06/she-figures-2012_en.pdf

European Commission. 2016. She Figures 2015: Gender in research and innovation, statistics and indicators. Luxembourg: Publications Office of the European Union. Available at https:/ / ec.europa.eu/research/swafs / pdf/pub_gender_equality/she_figures_2015 -final.pdf

Fox, Mary F., Carolyn Fonseca, and Jinghui Bao. 2011. «Work and family conflict in academic science: Patterns and predictors among women and men in research universities». Social Studies of Science 41(5): 715-735. DOI: https: / / doi.org/ 10.1177 / 0306312711417730

Gubler, Martin, John Arnold, and Crispin Coombs. 2014. «Reassessing the protean career concept: empirical findings, conceptual components, and measurement». Journal of Organizational Behaviour 35(S1): S23-S40. DOI: https: / / doi.org/10.1002/job.1908

Hewlett, Sylvia A., Carolyn B. Luce, Lisa J. Servon, Laura Sherbin, Peggy Shiller, Eytan Sosnovich, and Karen Sumberg. 2008. The Athena factor: reversing the brain drain in science, engineering and technology. Boston: Harvard Business Review.

Hill, Catherine, Christianne Corbett, and Andresse St Rose. 2010. Why so few? Women in science, technology and mathematics. Washington DC: AAUW. Available at http: / / www.aauw.org/ research/why-so-few/

Lubinski, David, and Camilla P. Benbow. 2007. «Sex differences in personal attributes for the development of scientific expertise». In Why aren't more women in science? Top researchers debate the evidence, edited by Stephen Ceci and Wendy Williams, 79-100. Washington, DC: American Psychological Association. DOI: https: / / doi.org/10.1037/11546-007

Mason, Mary A., and Marc Goulden. 2004. «Marriage and baby blues: Redefining gender equity in the academy». The Annals of the American Academy of Political and Social Science 596(1): 86-103. DOI: https: / / doi.org/10.1177/0002716204268744

Meyer, Jean-Baptiste, David Kaplan, and Jorge Charum. 2001. «Scientific nomadism and the new geopolitics of knowledge». International Social Science Journal 53(168): 309321. DOI: https: / / doi.org/10.1111/1468-2451.00317 
Perista, Heloisa, and Pedro Perista. 2014. «The impact of partnering, parenting and other caring responsibilities on SSH work and careers». POCARIM Policy Report 12. Available at https: / / www.salford.ac.uk/__data / assets / pdf_file/ 0020/532640/PR12_caring_november-HP-PP.pdf

Rodrigues, Ricardo A., and David Guest. 2010. «Have careers become boundaryless?» Human Relations 63(8): 1157-1175. DOI: https: / / doi.org/10.1177/ 0018726709354344

Sommerlund, Julie, and Sami Boutaiba. 2007. «Borders of the boundaryless career». Journal of Organizational Change Management 20(4): 525-538. DOI: https:/ / doi.org/10.1108/ 09534810710760063

Debbie Millard. Associate research fellow at the University of Salford, UK. Her main research interests lie in in the organizational field. She has worked on a range of research projects related to organizational learning, innovation, university-industry links and science careers, including research utilization of social science research, inter-sectoral and international mobility of researchers and reconciling work and family and women in academic careers.

Article received on October 23, 2015 and accepted for publication on October 20, 2016. 